\title{
Design and Implementation of Automatic Shooting Test System
}

\author{
Weilin Wang*, Li Wang and Huibin Kang \\ Physical Education College of Gannan Normal University, Ganzhou Jiangxi, 341000, China
}

\begin{abstract}
With the continuous development of science and technology in recent years, computers have been applied gradually in all fields. In physical education, automatic shooting test system is widely applied. In the paper, single chip microcomputer basket automatic shooting test system is taken as object of study. The system can clearly show, print and record scores. With the continuous promotion of technical system, the system plays an important role in physical education. It overcomes the disadvantages of original manual test, can effectively prevent fraudulent practices, and lays a solid foundation for boosting scientific and informationalized development of sports test. This paper will take the application of the system as the focus of study and make detailed analysis on the design and implementation of the system.
\end{abstract}

Keywords: Automatic test system, automatic test, single chip microcomputer.

\section{INTRODUCTION}

Shooting is one of the most important training and test items of basketball players, and it is of great importance to improving players' comprehensive basketball ability. The original test system adopts manual timing, manual reporting and manual recording, which is very easy to make mistakes. To ensure the accuracy of basketball examination, automatic test software should be applied in practice to be open and fair, and select excellent sports talents scientifically. The basketball automatic shooting test system involved in the study can accurately test the number of shootings, effectively realize automation of physical examination, reduce mistakes of manual operation, and effectively prevent fraudulent practices in examination.

\section{SYSTEM HARDWARE COMPOSITION AND OP- ERATING PRINCIPLE}

\subsection{System Hardware Composition}

After being connected with microcomputer shooting counter, the system can effectively record basketball test data collected by the computer and communicate with on-site scoring workstation through $\mathrm{RS} 232 \mathrm{C}$ serial port. Counter server should make up a local area network with on-site scoring workstation through concentrator and should score at all times [1]. See Fig. (1) for the design procedure chart of automatic shooting test system.

\subsection{Hardware Structure Of Shooting Counter}

Microcomputer shooting counter is equipped with the core device of 89C51 microprocessor and expands one 8255 programmable 1/0 chip as keyboard and display interface. To show scores strikingly, the displayer adopts 4" ultra-high brightness 8-section LED digital tubes. The series port MAX232 of single chip microcomputer is changed into RD232 electrical level for communicating with PC [2, 3]. It has "Start", "Stop" and "Foul" keys. To meet the demand of different application occasions, it has a change-over switch of "stand-alone" and "on-line". It can be used independently and jointly with PC. To adapt to the demand of different test methods, it has a change-over switch of "timing for $1 \mathrm{~min}$ " and "timing for $1.5 \mathrm{~min}$ " and a change-over switch of "timing shooting" and "shooting with definite number".

\subsection{Operating Principle of Shooting Counter Sensor}

Shooting counter sensor is a key factor to ensure the normal running of the system. Since basketballs have different sizes, there is no rule to follow when shooting in basket. To ensure accuracy of measurement and avoid fumble, automatic shooting test system should be adopted. As to the fixed calculation system adopted in the study, through repeated comparison and analysis, a conical basket welded with flat iron is adopted according to the change trend and application type of the sensor, the microswitch with flexible feeler level is fixed on the lower iron hoop, and the shooting counting sensor is fixed on the net. See Fig. (2) for detailed application form.

The sensor can be fixed on the net when the basketball is fixed on the lower cushion, the basketball will move up and down when getting into the basket, and the circular cone will deform and be cylindrical due to the shape difference of basket shooting counter sensor. Other factors should also be considered when setting basketball shooting counter. Since the diameter of the lower iron hoop is slightly greater than that of regular basketball, the side-to-side swing momentum of the basketball is basically zero, and will not repeatedly affect microswitch and further cause mistakes. To prevent the miss, the length of feeler level of the microswitch should be controlled to ensure that the smallest basketball can effectively touch the feeler level to make the microswitch closed reliably. When the biggest basketball is shot into the basket, 


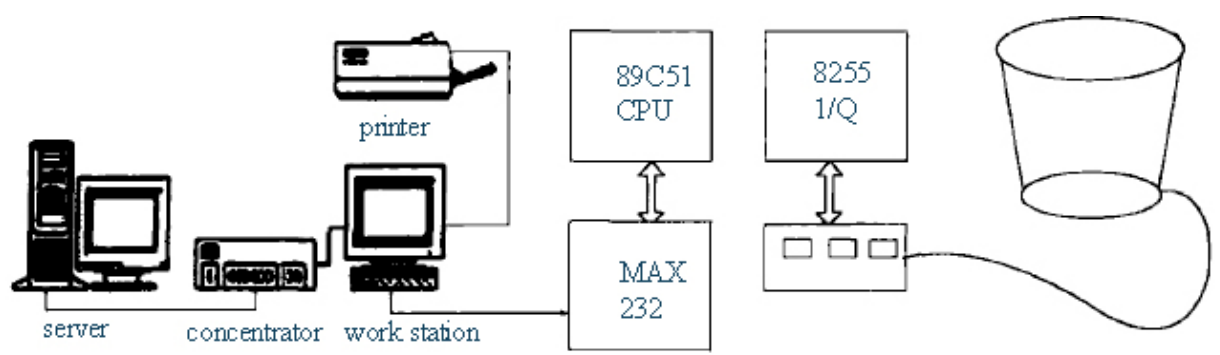

Fig. (1). System connection and composition of microcomputer shooting counter.

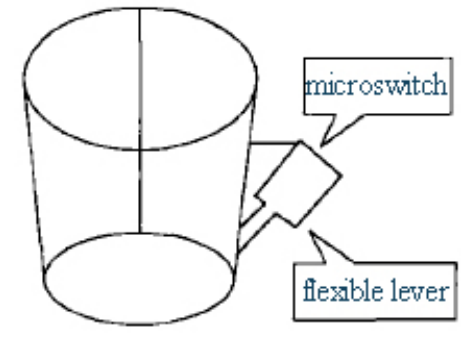

Fig. (2). Schematic diagram for fixing of microswitch.

since the feeler level of the microswitch has certain elasticity, it will not be seized up in the lower iron hoop, which not only ensures accurate counting but also avoid mistakes.

\subsection{Communication Between Single Chip Microcom- puter With PC}

During the system application, the accuracy of the communication between basketball shooting counter and PC is a key factor which affects data collection. Due to the essential difference between the two, RS232C interface is adopted. As to the setting of the interface, since PC terminal adopts ASC code for interpreting, unitary parity can not be adopted. Since single chip microcomputer adopts serial communication format, PC will send the data received to single chip microcomputer, and single chip microcomputer will resend the data. If the application result is similar, it will not resend the data again, so as to avoid data repeatability. When waiting for sending the next group of data, if it fails to send data timely, it will resend until $\mathrm{PC}$ receives the data correctly.

\section{SYSTEM SOFTWARE DESIGN}

\subsection{Microcomputer Shooting Counter Software}

Automatic test system adopts MCS-51 assembly language programming system. It mainly involves system initialization, keyboard scanning and main program indicator. Click "Start" and "Stop" to operate the system, use multiple keyboard functions, master the correlation between score counting program and communication program, and make an analysis according to the established flow chart. After power on reset or manual reset, initialization should be done first; RAM, 8255 working mode and test method should be preset; timing test should be done only after hardware self detection is done and the system is confirmed to be in good condition. When it starts, the number of scores should be counted. If the counter shows "J" on the screen, the latter two digits are the number of scores. To dovetail with PC communication technology, deduct an effective score by pressing "Foul" key if there is a foul. If the screen shows " $\mathrm{C}$ " after it stops, the latter two digits are invalid. To ensure system reliability, power filter is not adopted, sensor technology should be adopted for design, and technologies such as instruction redundancy and software traps are used in the operation process of counter software, so as to ensure the accuracy of shooting counter $[4,5]$.

\subsection{Score Recording Software On Test Site}

The system is set through the client side. Borland Delphi6.0 Visual Programming Language should be used in the process of setting. It is mainly used to collect the scores made by the preset basketball shooting counter to computer program through the established operating system. For the convenience of the admission office to collect and input data, new file system should be formed continuously, and all data in database should be analyzed and summarized according to the operating behavior and application way of the file system [6]. Data of additional scores should be transmitted to the master server through local area network and shown, recorded and printed on site. See Fig. (3) for main functional modules of the system.

\subsection{Server Side Database Management Software}

In this study, during the process of design and statistics with automatic shooting test system, statistics on download database information should be done, and card number and

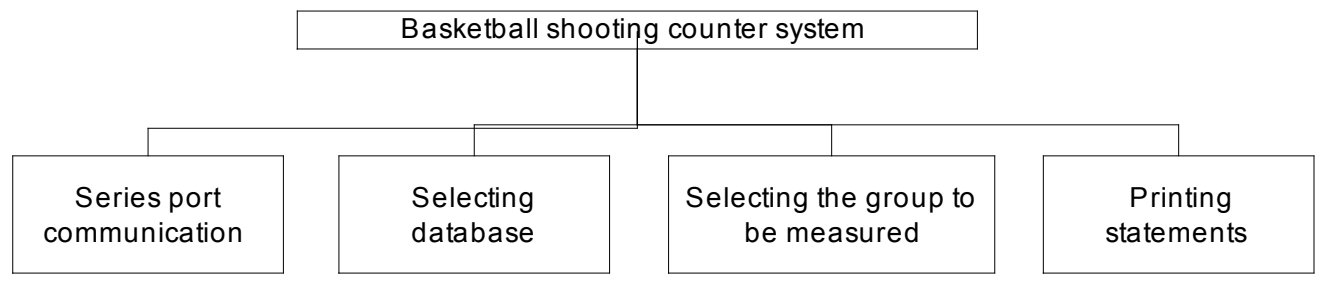

Fig. (3). Main functional modules of the system. 


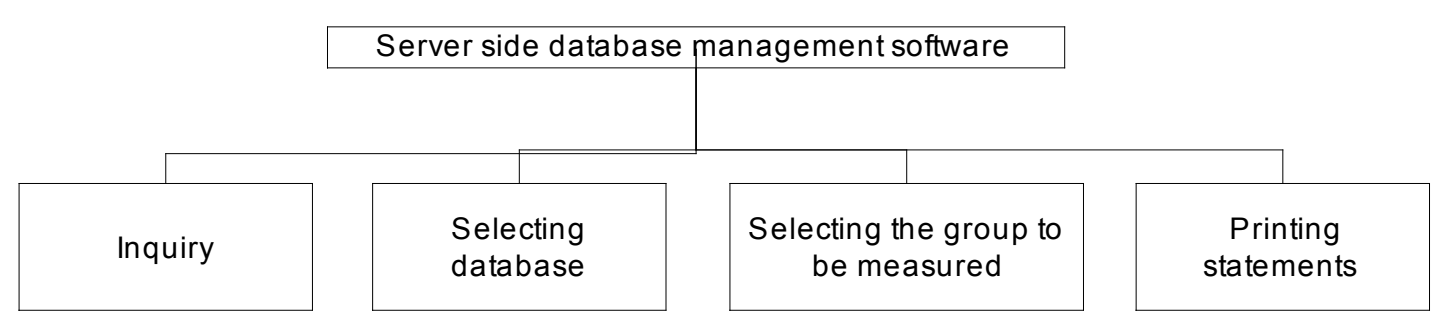

Fig. (4). Main functional modules of server side database management software.

user name should be input. Since the application system is integrated, integration design concept should be adopted. The relevant personnel should figure out the operation procedure and analyze and apply the program as per the required way and application concept. See Fig. (4) for main modules of the system.

\subsection{Analysis On Design Procedure}

Based on the particularity of the application, in order to improve practice effect of the application, the relevant procedure should be analyzed in detail in clinical practice. Systematic analysis on design procedure is made below.

\subsubsection{Improve Staff Quality}

Aiming at the importance of collecting automatic basketball shooting test data, the relevant personnel should make clear their duties and conduct practical operation according to the established procedure. The system involves sensor system, microswitch fixing device and the relevant communication technology and these applications have close relations. To reach ideal application effect, the operation way and application way of the automatic shooting test system should be defined. Since automatic control system also needs manual operation, the range of application and probability of increase of the application system should be mastered. Staff should have the consciousness of responsibility. Aiming at the design problem and application disadvantages of automatic shooting test system, staff should conduct monitoring and analysis in time and should know about the factors involved on the basis of the existing application system.

\subsubsection{Enhance the Management to Application Software}

In the study, the building of local area network is involved, to record the actual scoring of the whole system software, the routine management procedure of the test workstation should be defined in daily practice, and management should be done according to student number and results inquiry. Since computer application system is in serial work state, to ensure data accuracy, operators can conduct detailed analysis and statistics to the relevant counting information and design procedure through microcomputer. Since the input and application of additional scores may be involved in practice, the limit of local area network should be broken through and real-time analysis and application of all data should be done. Due to the diversity of system software, sort management for software system should be done in application process to avoid the disadvantages of the original system, and analysis and summary should be done according to the established application system and procedure, so as to lower miss probability.

\subsubsection{Define Collection Steps}

Since the automatic shooting test system involves many collection ways and application contents, to reduce the interference of other factors, collection steps should be defined and analysis on the relevant contents should be done according to actual situation. Since high-speed collection and input system is affected by many factors, the established programming language should be used to conduct analysis and summary. "Start" key expresses $7 \mathrm{CH}=1$, the displayer shows " 1 " and " $4 "$ ", and "Y" is the sign of counting information. "Score" key is mainly used to record the number of scores, and it involves PC detection system and generation system. To ensure the accuracy of the application system, LED should be pushed, and analysis and statistics for results should be done according to displayer data. Since "Foul" key is pressed after "Score" key, in order to analyze score record, the integrated analysis on generation record should be made, and analysis on the results shown by the displayer should be done according to LED influence system, and one score should be deducted from score record. When pressing "stop" key, sign and timing record should be removed. To prevent from the influence of other factors, integrated analysis on onsite results recording software and server side database management software should be done, and the collection and application of automatic shooting test system data should be done according to the established operation way and application procedure.

\section{CONCLUSION}

In the study, computer single chip serial system is taken as object of study. To reflect the practicalness of the system, strong data concept and relevant communication technology are used to analyze and sort out data according to the established management procedure and application concept. The automatic shooting test system gets rid of the disadvantages of the original application system, involves the procedures of data collection, keyboard input and display, and it integrates all application systems and concepts into basketball test through appropriate debugging and development. Due to the particularity of application system, to improve test effect and ensure data accuracy, debugging and test should be done continuously and repeatedly, and effective analysis and application of the system mode should be done. Simultaneously, with the continuous development of the change trend of physical education subject in college entrance examination, automatic basket shooting test system should be perfected and further reach the expected application effect. 


\section{CONFLICT OF INTEREST}

The authors confirm that this article content has no conflict of interest.

\section{ACKNOWLEDGEMENTS}

Declared none.

\section{REFERENCES}

[1] P. Liu, L. Jia, and G. Hu, "Design and Implementation of Infrared Lead Automatic Test System Based on Virtual Instrument," Nei Jiang Science \& Technology, no. 19, pp. 90-93, 2011.
[2] G. Cui, X. Qi, J. Ji, and J. Feng, "Design and Implementation of Automatic Test System of Aircraft Gun Integrated Control Device," Journal of Gun Launch \& Control, vol. 19, no. 10, pp. 90-93, 2011.

[3] Z. Fan, D. Zhou, K. Wang, and T. Liu, "Design and Implementation of Airborne Audio Management Unit Automatic Test System," Computer Measurement and Control, no. 19, pp. 70-73, 2011.

[4] S. Guo, and J. Liang, "Design and Implementation of Automatic Test System Software Framework" Computer Measurement \& Control, vol. 19, no. 20, pp. 300-304, 2011.

[5] B. Xu, and Z. Xie, "Design and Implementation of TD-LTE Terminal Radio Frequency Consistency Automatic Test System," Video Engineering, vol. 18, no. 20, pp. 70-72, 2011.

[6] W. Feng, "Design and Implementation of Electromagnetic Leakage Launch Automatic Test System Based on Virtual Instrument," Secrecy Science and Technology, no. 19, pp. 80-83, 2011.

Received: June 10, 2015

Revised: July 29, 2015

Accepted: August 15, 2015

(C) Wang et al.; Licensee Bentham Open.

This is an open access article licensed under the terms of the (https://creativecommons.org/licenses/by/4.0/legalcode), which permits unrestricted, noncommercial use, distribution and reproduction in any medium, provided the work is properly cited. 